\title{
Dilemma of migraine diagnosis and management among non-neurologists
}

\author{
Mai Fathy ${ }^{*} \mathbb{B}$, Ahmed ElSadek, Sherien Farag, Shahinaz Helmy and Amr AbdEIMoneim
}

\begin{abstract}
Background: Migraine is a common and debilitating disorder however there is a wide gap in its diagnosis and management. Many migraine patients present to non-neurologists, so it is of utmost importance that non neurologists become well oriented with the diagnostic criteria and different lines of management. The aim of the study was to assess the knowledge and attitude of non-neurologists towards migraine.

Results: About $45 \%$ of physicians in our study refer migraine patients to non-neurologists, only $20.96 \%$ are aware of both classic and novel treatments, $43 \%$ had poor knowledge of migraine symptoms and management, 32.34\% recommended using medical tailored programs to increase the awareness of non-neurologists regarding migraine.
\end{abstract}

Conclusions: There is a wide gap of knowledge concerning migraine among non-neurologists.

Keywords: Headache, Migraine, Diagnosis, Education

\section{Background}

Migraine affects more than $10 \%$ of the population worldwide. It is considered the second leading cause of years lived with disability [1]. Despite the availability of international guidelines for migraine diagnosis and treatment $[2,3]$, the management of migraine is still far from ideal as many of the patients did not reach a medical diagnosis and did not receive proper acute and preventive treatment [4]. This could be due to many reasons; including lack of public awareness, physician knowledge and that the management of headache patients could be by a primary physician or other specialties that are not aware of the proper diagnosis and management of migraine [5]. It was estimated that $80 \%$ of patients seen by primary care physicians are migraneurs and that less than $20 \%$ are correctly diagnosed and treated [6,7]. And according to the WHO, $50 \%$ of headache patients are self-treated and only $10 \%$ are seen by a neurologist [8]. Since most patients with migraine did not receive a correct diagnosis, they mostly depend on over the counter analgesics which if

\footnotetext{
*Correspondence: maifathy23@gmail.com

Neurology Department, Faculty of Medicine, Ain Shams University, Cairo, Egypt
}

used too frequently can lead to medication overuse headache leading to more disability [1]. And this is more evident in the developing countries [8]. In Egypt, the studies for migraine prevalence and management are scarce, the prevalence of migraine was found to be $10.5 \%$ in a study done in Assiut government [9], another recent study was done in Upper Egypt showed that the life time prevalence of migraine was $3.38 \%$. The prevalence of migraine was found to be $17 \%$ in another study [10], and despite its effect on quality of life, only $8.5 \%$ of the patients received preventive treatment [11]. At our country many of the headache patients are seen by physicians other than neurologists, who could be a family doctor, ophthalmologist, otolaryngologist, cardiologist, internal medicine physician or others, this could lead to a proper treatment gap, so our study aimed to evaluate the knowledge and awareness of the non-neurologist doctors about migraine diagnosis and management.

\section{Methods}

This study was a cross-sectional study. A self-developed questionnaire was used. One hundred sixty seven physicians from different specialties were included in this study and completed a self-administered questionnaire 
that was sent online including the informed consent (Additional file 1). The questionnaire included 36 questions regarding; age, years of experience and specialty, questions regarding referral, causes of migraine, precipitating factors, associated symptoms, clinical characteristics, management, how they obtained their knowledge and how do they prefer to obtain further knowledge. Questions assessing knowledge were structured as direct questions with three answering options (yes, no, or I do not know), regarding questions with one correct answer a point was scored for the correct answer, regarding questions with more than one correct answer a point was scored for participants who chose $\geq 50 \%$ correctly. Participants who scored $<50 \%$ correct answers were considered to have poor knowledge, participants who scored $50-70 \%$ correct answers were considered to have average knowledge, participants who scored $>70 \%$ correct answers were considered to have good knowledge.

\section{Statistical analysis}

Descriptive data were represented as mean and standard deviation for continuous variables and as number and percentage for categorical ones. The chi-square test was used to compare categorical variables, with statistical significance set at $p<0.05$. The analysis was done on SPSS ver. 25(IBM SPSS, NY, USA, 2017).

\section{Results}

The study included 167 participants. The mean age of the participants was $37.311 \pm 6.846$ with mean years of experience of $12.826 \pm 6.720$. The study included $58(34.73 \%)$ internal medicine physicians, 31(18.56\%) ophthalmologists, 26(15.57\%) otolaryngologists, 24(14.37\%) cardiologists, $17(10.18 \%)$ neurosurgeons and 11(6.59\%) emergency medicine physicians. Most of the participants 91(54.49\%) accounted that they refer their patients to neurologists, however $76(45.51 \%)$ accounted that they refer their patients to non-neurologists; 30 (17.96\%) to internal medicine, 25(14.97\%) to otolaryngologists, $19(10.78 \%)$ to ophthalmology and 3(1.8\%) to others. Most of the participants $128(76.65 \%)$ accounted that mild (140 to $159 / 90$ to $99 \mathrm{mmHg}$ ) or moderate (160 to $179 / 100$ to $109 \mathrm{mmHg}$ ) chronic arterial hypertension can cause headache. Among the participants, 145 (86.83\%) had the knowledge that headache can be a primary disorder, 132(79.04\%) had the knowledge that it can be a treatable disorder. Knowledge regarding precipitating factors of migraine is demonstrated in Fig. 1. Knowledge regarding clinical characteristics of migraine is demonstrated in Table 1. Knowledge regarding effect of migraine on fertility and daily functions is demonstrated in Fig. 2. Regarding the associated symptoms of migraine, the most known symptoms were vomiting $130(77.84 \%)$, photophobia $128(76.65 \%)$, phonophobia $127(76.05 \%)$ and mood changes 107(64.07\%) (Fig. 3), 31(19.57\%) participants

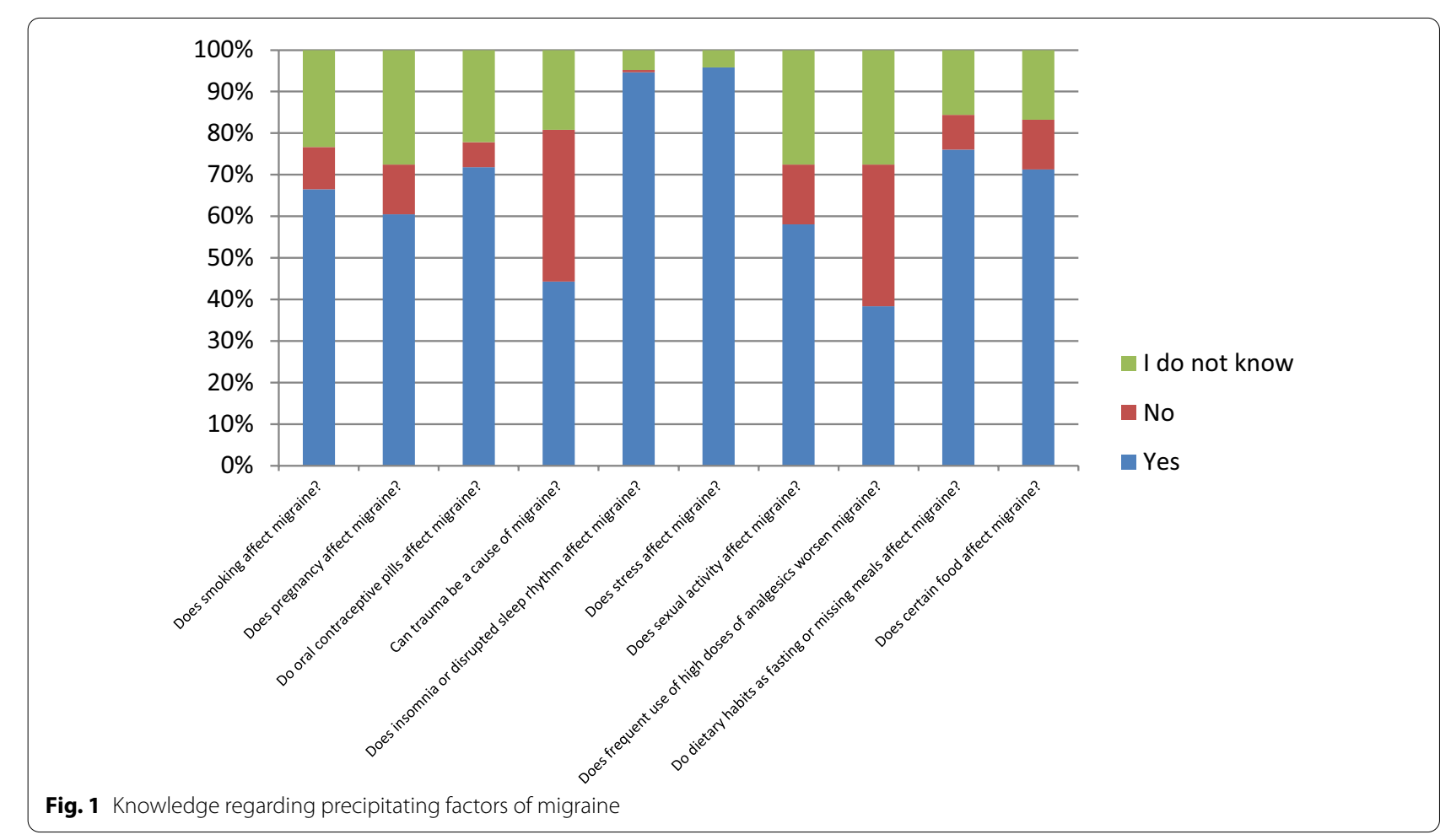


Table 1 Knowledge regarding clinical characteristics of migraine

\begin{tabular}{|c|c|c|}
\hline & & $n(\%)$ \\
\hline \multirow[t]{4}{*}{ What is the common age of migraine onset? } & Less than 20 years & $23(13.77)$ \\
\hline & 20-40 years & $127(76.05)$ \\
\hline & More than 40 years & $5(2.99)$ \\
\hline & I do not know & $12(7.19)$ \\
\hline \multirow[t]{4}{*}{ How long does the migraine attack last? } & Less than $4 \mathrm{~h}$ & $24(14.37)$ \\
\hline & $4-72 \mathrm{~h}$ & $122(73.05)$ \\
\hline & More than $72 \mathrm{~h}$ & $7(4.19)$ \\
\hline & I do not know & $14(8.38)$ \\
\hline \multirow[t]{4}{*}{ Is migraine commonly } & Unilateral & $120(71.86)$ \\
\hline & Bilateral & $9(5.39)$ \\
\hline & Both & $35(20.96)$ \\
\hline & I do not know & $3(1.80)$ \\
\hline \multirow[t]{7}{*}{ What is the most common character for migraine? } & Dull aching & $26(15.57)$ \\
\hline & Numbness & $2(1.20)$ \\
\hline & Pressure tight band & $24(14.37)$ \\
\hline & Throbbing & $82(49.10)$ \\
\hline & Burning & $3(1.80)$ \\
\hline & Stabbing & $23(13.77)$ \\
\hline & I do not know & $7(4.19)$ \\
\hline \multirow[t]{6}{*}{ What is the most common site for migraine? } & Forehead & $27(16.17)$ \\
\hline & Vertex & $14(8.38)$ \\
\hline & Temple & $84(50.30)$ \\
\hline & Behind eyes & $29(17.37)$ \\
\hline & Back of head & $5(2.99)$ \\
\hline & I do not know & $8(4.79)$ \\
\hline \multirow[t]{3}{*}{ What is the usual onset for migraine? } & Sudden/abrupt & $59(35.33)$ \\
\hline & Gradual & $100(59.88)$ \\
\hline & I do not know & $8(4.79)$ \\
\hline
\end{tabular}

were aware of $\geq 10$ of associated symptoms of migraine. Regarding the knowledge concerning management of migraine, $9(5.39 \%)$ reported that migraine patients require preventive treatment, $13(7.78 \%)$ reported that they require acute treatment and $145(86.83 \%)$ reported that they require both, $98(58.68 \%)$ accounted that they are well aware of classic treatments (antiepileptic drugs, antidepressants, $\beta$ blockers and calcium channel blockers), 5(2.99\%) are well aware of novel treatments (Botulinum toxin injection, monoclonal antibodies and nerve block) and 35(20.96\%) are well aware of both (Figs. 4,5). When asked about how did the participants mainly learned about migraine and its management 106(63.47\%) accounted that they received most of their knowledge from undergraduate lectures, 32(19.16\%) from medical conferences, $16(9.58 \%)$ from medical tailored programs and $13(7.78 \%)$ from social media, and when asked about what do they think is the best way to increase physician's awareness about migraine, 54(32.34\%) recommended using medical tailored programs, 48(28.74\%) recommended medical conferences, 43(25.75\%) recommended social media and $22(13.17 \%)$ recommended undergraduate lectures (Table 2). Only 7(4.19\%) had good knowledge of migraine, $88(52.69 \%)$ had average knowledge and $72(43.11 \%)$ had poor knowledge. There was significant difference in knowledge regarding years of experience being higher in participants with more years of experience $(p=0.022)$, there was significant difference showing poor knowledge among participants who gained their knowledge mainly through undergraduate lectures $(p=0.001)$, and significantly better knowledge among participants who prefer medical tailored programs $(p=0.010)$. However there was no significant difference in knowledge between participants with different specialties (Table 3).

\section{Discussion}

There is a knowledge gap regarding migraine among nonneurologists and more over there is paucity of research from low and middle income countries. Increasing the 


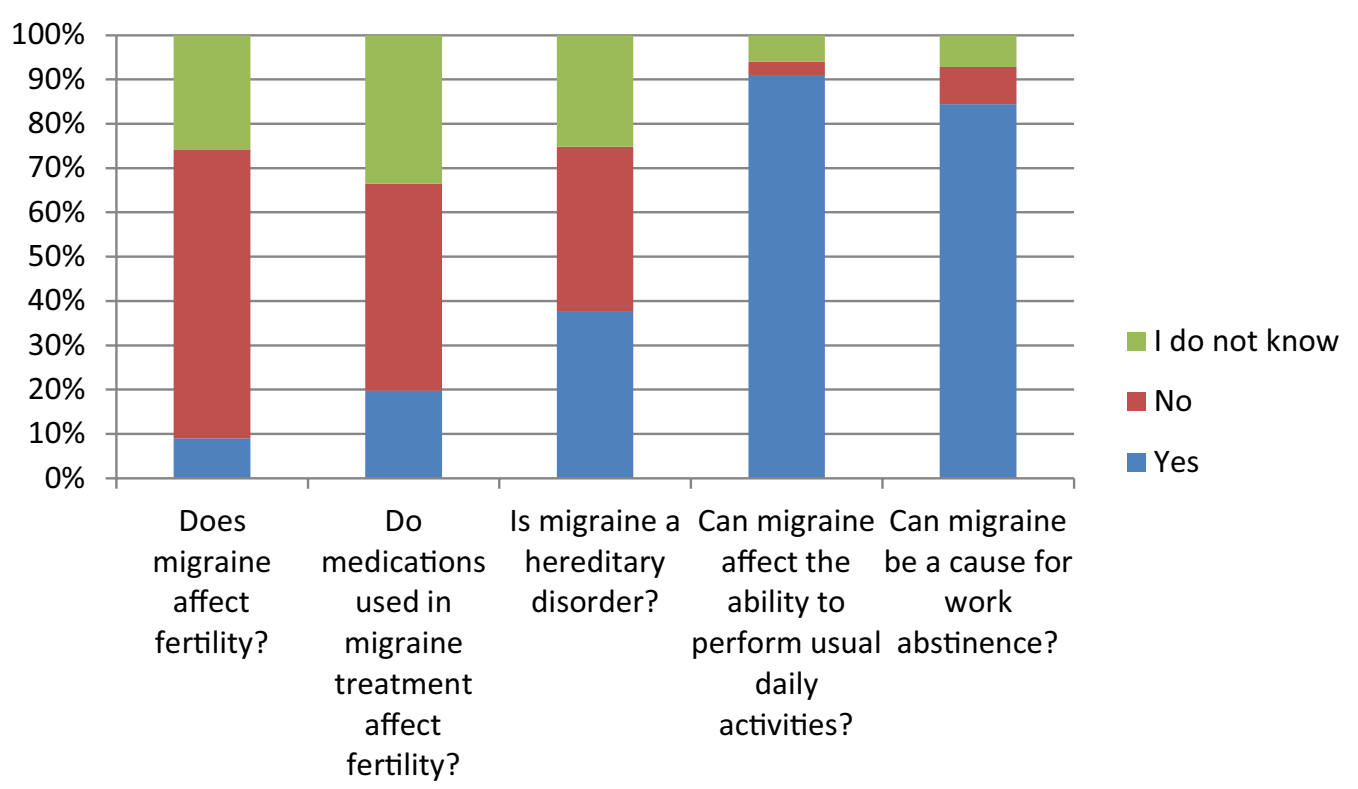

Fig. 2 Knowledge regarding effect of migraine on fertility and daily functions

ฉำ
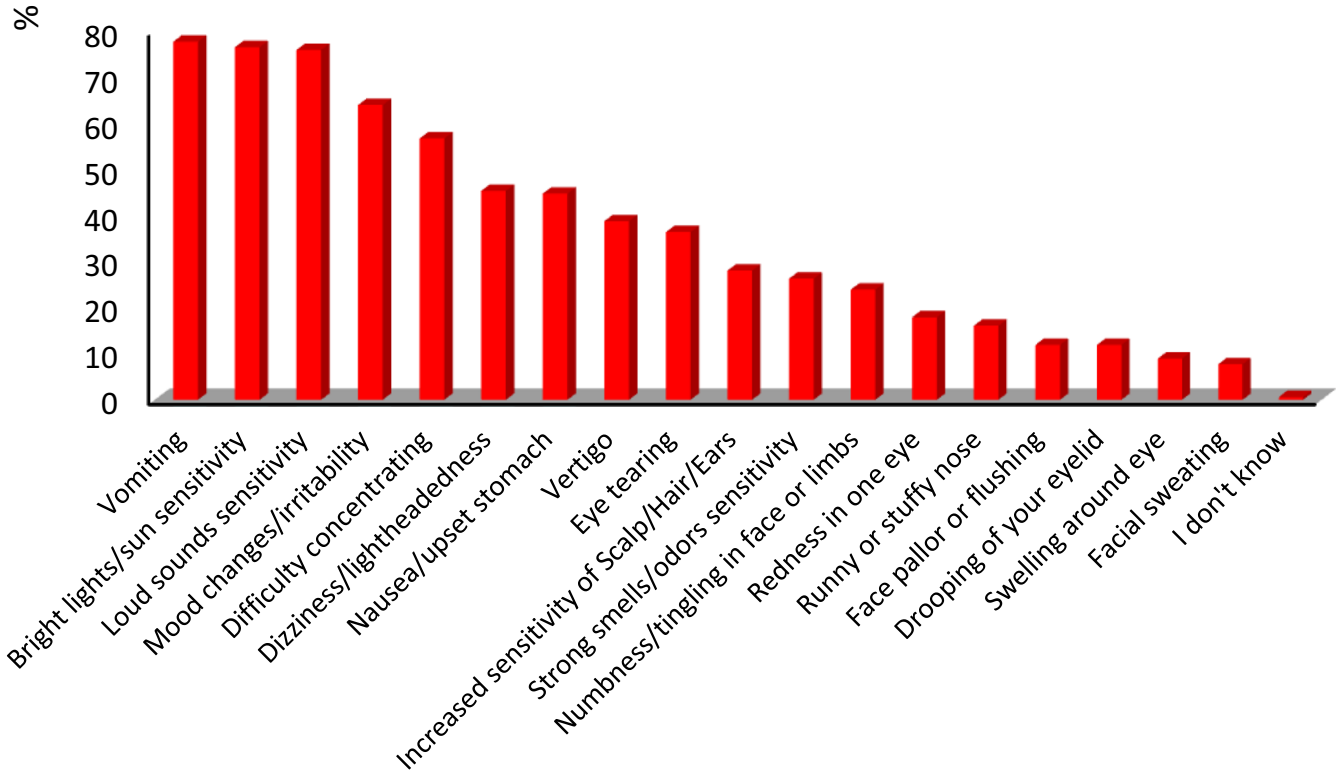

Fig. 3 Knowledge regarding associated symptom of migraine

awareness of primary care physicians and other medical specialties is mandatory to improve the attitude towards referral and treatment $[12,13]$. This knowledge gap impacts the management of migraine patients and interferes with reaching a proper diagnosis. In a study conducted in England, it was found that two-thirds of patients did not receive proper diagnosis for their headache from primary care physicians [14]. In this study only $4.19 \%$ of participants were able to achieve good knowledge of clinical characteristics and management tools of migraine. Gültekin and colleagues showed that only $10.5 \%$ of their participants were able to complete the diagnostic criteria of migraine [15]. Also a study done in Jeddah showed that primary care physicians had 


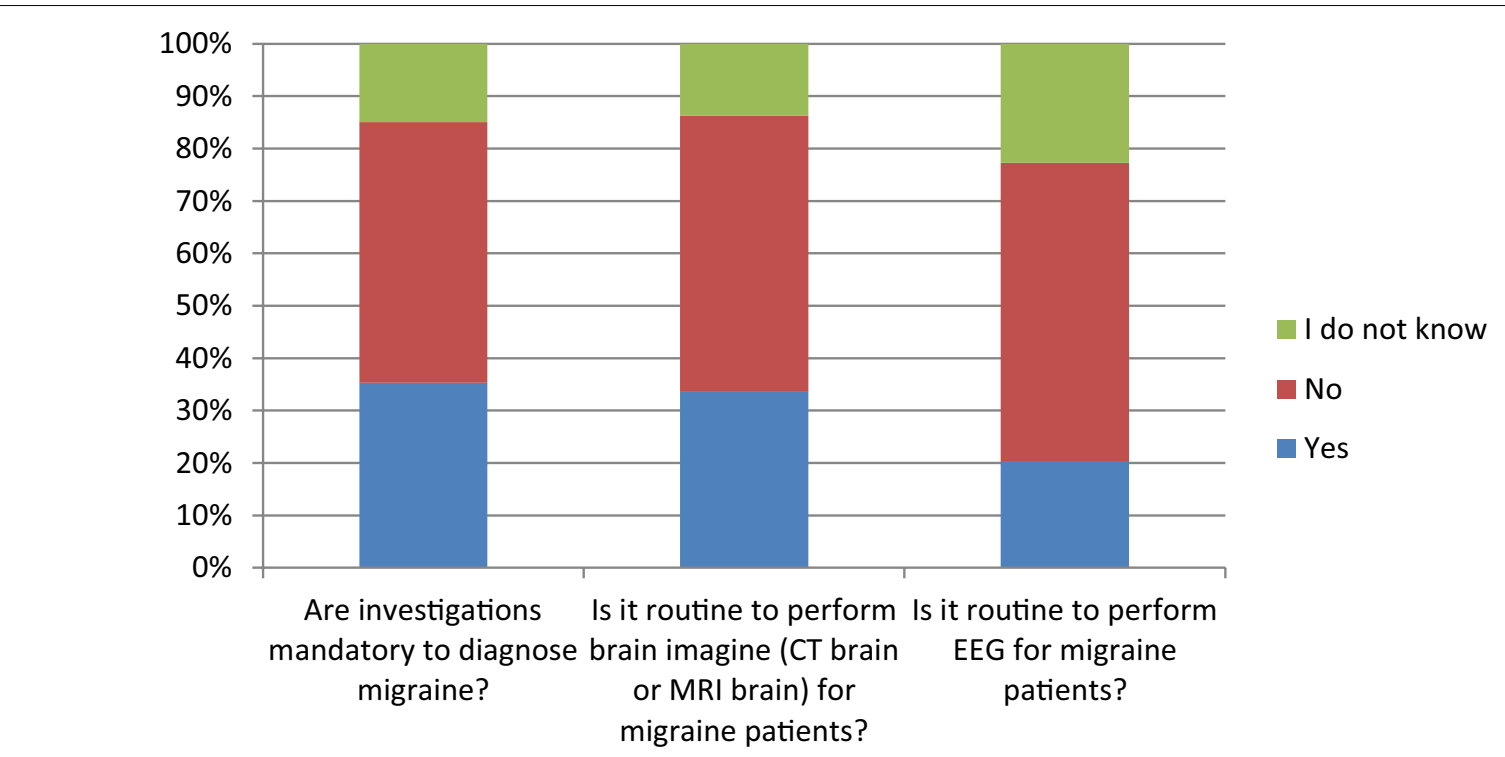

Fig. 4 Knowledge regarding investigations for migraine. CT computed tomography, MRI magnetic resonance imaging, EEG electroencephalogram

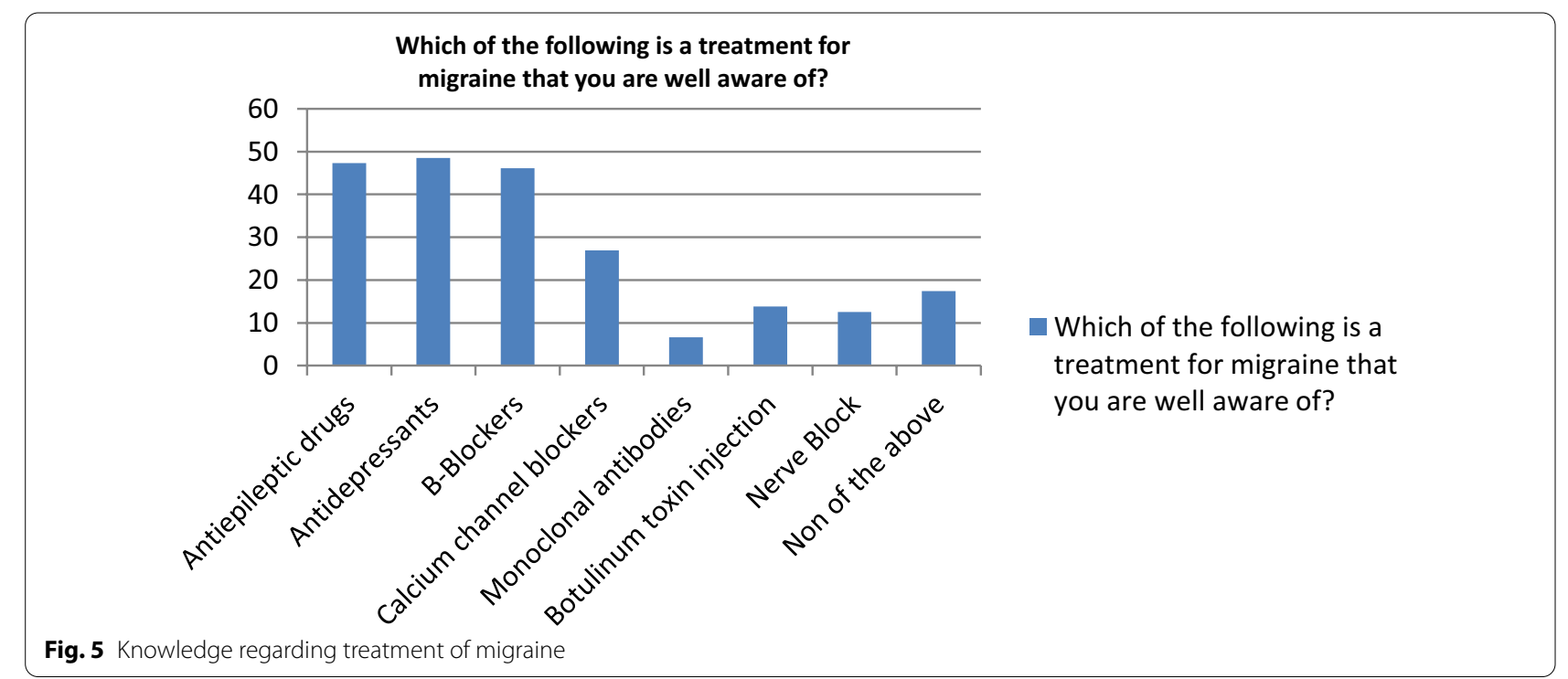

low knowledge levels and inappropriate attitudes toward chronic migraine [16]. This study showed that $54.49 \%$ will refer headache patients to a neurologist, indicating poor referral. Mehrotra mentioned that only $5 \%$ of general physicians refer headache patients to neurologists [17]. Electroencephalogram (EEG) is not an essential tool to diagnose or follow up migraine patients [18], however $20.36 \%$ of the participants said that they consider it a routine to order EEG for migraine patients. Verhaak and colleagues mentioned that $35 \%$ of medical practitioners will order brain imaging for new onset headache [19]. Patients with normal examination and typical clinical presentation will only have $0.18 \%$ significant brain pathology [20] hence, it is unnecessary to perform brain imaging for the vast majority of migraine patients, however $33.53 \%$ of the participants consider it a routine to perform brain imaging for migraine patients. The study showed that $86.83 \%$ will use both preventive and abortive therapy in the management of migraine. Takaki and colleagues stated that physicians are reluctant in prescribing preventive therapy and more over the patients are hesitant to use those drugs [21], 58\% said they will use the classic treatments. Takaki 
Table 2 Physician's preference regarding increasing awareness:

\begin{tabular}{|c|c|c|c|c|}
\hline \multirow[t]{3}{*}{ Specialty } & \multicolumn{4}{|c|}{ What do you think is the best way to increase physician's awareness about migraine? } \\
\hline & Undergraduate lectures & Medical conferences & Social media & $\begin{array}{l}\text { Medical } \\
\text { tailored } \\
\text { program }\end{array}$ \\
\hline & $n(\%)$ & $n(\%)$ & $n(\%)$ & $n(\%)$ \\
\hline Neurosurgery & $2(9.09)$ & $5(10.42)$ & $1(2.33)$ & $9(16.67)$ \\
\hline Ophthalmology & $1(4.55)$ & $9(18.75)$ & $9(20.93)$ & $12(22.22)$ \\
\hline Otolaryngologists & $7(31.82)$ & $6(12.50)$ & $8(18.60)$ & $5(9.26)$ \\
\hline Internal medicine & $8(36.36)$ & $17(35.42)$ & $13(30.23)$ & $20(37.04)$ \\
\hline Cardiology & $1(4.55)$ & $7(14.58)$ & $8(18.60)$ & $8(14.81)$ \\
\hline Emergency medicine & $3(13.64)$ & $4(8.33)$ & $4(9.30)$ & $0(0.00)$ \\
\hline
\end{tabular}

Table 3 Comparing knowledge among non-neurologists with methods of education

\begin{tabular}{|c|c|c|c|c|c|}
\hline & & \multicolumn{2}{|c|}{ Headache knowledge } & \multicolumn{2}{|c|}{ ANOVA } \\
\hline & & $N$ & Mean \pm SD & $F$ & $P$-value \\
\hline \multirow[t]{4}{*}{ How did you learn about migraine and its management? } & Undergraduate lectures & 106 & $28.198 \pm 7.045$ & 11.158 & $<0.001^{*}$ \\
\hline & Medical conferences & 32 & $25.031 \pm 7.329$ & & \\
\hline & Social media & 13 & $19.308 \pm 5.513$ & & \\
\hline & Medical tailored program & 16 & $33.063 \pm 6.351$ & & \\
\hline \multirow{4}{*}{$\begin{array}{l}\text { What do you think is the best way to increase physician's } \\
\text { awareness about migraine? }\end{array}$} & Undergraduate lectures & 22 & $24.273 \pm 7.192$ & 3.901 & $0.010^{*}$ \\
\hline & Medical conferences & 48 & $26.688 \pm 7.452$ & & \\
\hline & Social media & 43 & $26.442 \pm 8.172$ & & \\
\hline & Medical tailored program & 54 & $29.963 \pm 6.619$ & & \\
\hline
\end{tabular}

and colleagues also stated that anticonvulsants are less prescribed by primary care physician, while $\beta$-blockers and anti-depressants are prescribed almost equally by primary care physicians and specialized care physicians [21]. Higher years of experience were significantly correlated to better knowledge, indicating the important role of clinical experience in enhancing knowledge. The majority of participants pointed out under graduate lectures as the major source of knowledge about migraine headache. Patwardhan and colleagues mentioned that continued medical education programs poses significant impact on knowledge and attitude of physicians [22]. Migraine is one of the most common disabling diseases yet it is still under diagnosed, under estimated and under treated [23]. It is very important to provide medical tailored programs for non-neurologists to provide better care for such patients. The study had some limitations, as it mainly shed light on migraine rather than all types of primary headache as it was difficult to structure a longer questionnaire. Also the sample size limits the generalization of the findings without further larger scale studies. The strengths of this study are that it is one of the few studies done across different specialties, most studies address primary care physicians which is different from the health care system in Egypt. It is also the first study to shed light on the knowledge gap among non-neurologists aiming to improve patients' outcome.

\section{Conclusions}

Knowledge regarding migraine diagnosis and treatment was unsatisfactory among non-neurologists. This has a major effect on the level of patients care and detrimentally affects the referral to neurologists consequently affecting the patient's diagnosis and management, so it is of utmost importance to address non-neurologists about different types of headache, how to diagnose and how to manage. Most of the participants preferred medical tailored program and social media. Undergraduate lectures proved to be the least effective method of education while medical tailored programs proved to be more effective, so it is important to address members of different specialties according to their preferred method and it is important to enhance the undergraduate programs with updated knowledge and shed light on the importance of such prevalent disorder to provide better management and lessen its burden. 


\section{Abbreviation}

EEG: Electroencephalogram.

\section{Supplementary Information}

The online version contains supplementary material available at https://doi. org/10.1186/s41983-021-00371-8.

Additional file 1. Questionnaire.

\section{Acknowledgements}

Not applicable.

\section{Authors' contributions}

MF: Designed and conceptualized the study, drafting the manuscript. AS: Conception of the work, manuscript revision. SF: data collection and research project execution. SH: data collection and research project execution. AA: Conception of the work, data collection, drafting the manuscript. The content of the manuscript has not been published, or submitted for publication elsewhere. All authors have agreed to conditions noted on the Authorship Agreement Form and have read and approved the final manuscript.

\section{Funding}

No funds were received to fulfill this work.

\section{Availability of data and materials}

The corresponding author takes full responsibility for the data, has full access to all of the data; and has the right to publish any and all data separate and apart from any sponsor.

\section{Declarations}

Ethics approval and consent to participate

All procedures performed in the study were in accordance with the ethical standards of the faculty of medicine, Ain Shams university research and ethical committee and with the 1964 Helsinki declaration and its later amendments or comparable ethical standards. We obtained approval from research ethics committee no. FWA 000017585. On 19/1/2021. Written informed consent was obtained from participants for participation. We obtained approval from research ethics committee no. FWA 000017585. On 19/1/2021.

\section{Consent for publication}

Not applicable.

\section{Competing interests}

None of the authors has any conflict of interest.

Received: 21 June 2021 Accepted: 18 Auqust 2021

Published online: 31 August 2021

\section{References}

1. GBD 2016 Disease and Injury Incidence and Prevalence Collaborators. Global, regional, and national incidence, prevalence, and years lived with disability for 328 diseases and injuries for 195 countries, 1990-2016: a systematic analysis for the Global Burden of Disease Study 2016. Lancet. 2017:390(10100):1211-59.

2. Evers S, Afra J, Frese A, Goadsby PJ, Linde M, May A, et al. European Federation of Neurological Societies. EFNS guideline on the drug treatment of migraine-revised report of an EFNS task force. Eur J Neurol. 2009;16(9):968-81.

3. Diener $H$, Tassorelli C, Dodick D, Silberstein S, Lipton R, Ashina M, et al. Guidelines of the international Headache Society for controlled trials of preventive treatment of migraine attacks in episodic migraine in adults. Cephalalgia. 2020; 40(10):1026-1044.

4. Ziegeler Ch, Brauns G, Jurgens T, May A. Short comings and missed potentials in the management of migraine patients. Experiences from a specialized tertiary care center. J Headache Pain. 2019;20(86):1-8.

5. Goodhew S. Migraine literacy and treatment in a university sample. SN Compr Clin Med. 2019;1:749-57.

6. Kernick D. Reducing the burden of headache: the international headache society primary care interest Group. Cephalagia. 2010;30:899-909.

7. Alzahrani F, Hmoud M, Khayat H, Farahat F, Manlangit J, Attar A. Knowledge of primary health care physicians about headache disorders: a cross-sectional study. Qual Prim Care. 2016;24(2):83-6.

8. Malik A, Awan S, Sonawalla A, Aimed F, Wasay M. Awareness and approach to headache: a survey of family physicians in Pakistan. Pak J Neurol Sci. 2018;13(4):5-10

9. Kandil M, Hamed Sh, Fadel K, Khalifa H, Ghanem M, Mohamed K. Migraine in Assiut Governorate, Egypt: epidemiology, risk factors, comorbid conditions and predictors of change from episodic to chronic migraine. Neurol Res. 2016;38(3):232-41.

10. Tallawy H, Farghaly W, Abdelhamed M, Badry R, Rageh T, et al. Prevalence of migraine in Upper Egypt. Egypt J Neurol Psychiatry Neurosurg. 2019;55:20.

11. El-Sherbiny NA, Masoud M, Shalaby NM, Shehata HS. Prevalence of primary headache disorders in Fayoum Governorate. Egypt J Headache Pain. 2015;16:85.

12. Charleston $L 4$ th, Heisler M. Headache literacy - a definition and theory to help improve patient outcomes of diverse populations and ameliorate headache and headache care disparities. Headache. 2016;56(9):1522-6.

13. Mateen F, Dua T, Steiner T, Saxena S. Headache disorders in developing countries: research over the past decade. Cephalalgia. 2008;28(11):1107-14

14. Kernick D, Stapley S, Hamilton W. GPs' classification of headache: Is primary headache underdiagnosed? Br J Gen Pract. 2008;58:102-4.

15. Gültekin M, Balci E, İsmailLĞULLARI S, Yetkin F, Baydemir R, Erdoğan F, et al. Awareness of migraine among primary care physicians in Turkey: a regional study. Noro Psikiyatr Ars. 2018:55(4):354-7.

16. Aljunaid MA, Jamal HH, Mubarak AA, Bardisi W. Levels and determinants of knowledge about chronic migraine diagnosis and management among primary health-care physicians in ministry of health, Jeddah 2019 J Fam Med Prim Care. 2020;9(5):2324-31.

17. Mehrotra C, Kanodia N, Shankar P, Sachan A, Dixit R. Knowledge, attitude and practice of general physicians related to migraine. World J Pharm Sci. 2015;3(12):2470-1.

18. Hamad M, Sheaheed M, Abdulrasool S, Almahdawi A. EEG changes in patients with migraine. IPMJ. 2014;13(2):156-60.

19. Verhaak AMS, Williamson A, Johnson A, Murphy A, Saidel M, Chua AL, et al. Migraine diagnosis and treatment: a knowledge and needs assessment of women's healthcare providers. Headache. 2021;61(1):69-79.

20. Holle $D$, Obermann $M$. The role of neuroimaging in the diagnosis of headache disorders. Ther Adv Neurol Disord. 2013;6(6):369-74.

21. Takaki H, Onozuka D, Hagihara A. Migraine-preventive prescription patterns by physician specialty in ambulatory care settings in the United States [published correction appears in Prev Med Rep. 2020 Dec 10;20:101282]. Prev Med Rep. 2017;9:62-7.

22. Patwardhan MB, Samsa GP, Lipton RB, Matchar DB. Changing physician knowledge, attitudes, and beliefs about migraine: evaluation of a new educational intervention. Headache. 2006;46(5):732-41.

23. Russo A, Lavorgna L, Silvestro M, Abbadessa G, Bisecco A, Trojsi F, et al. Readability analysis of online headache and migraine information. Headache. 2020:60(7):1317-24

\section{Publisher's Note}

Springer Nature remains neutral with regard to jurisdictional claims in published maps and institutional affiliations. 